\title{
GLP-1 analogues: a new therapeutic approach to prevent ductopenia in cholangiopathies?
}

\section{Ulrich Beuers, ${ }^{1}$ Burkhard Göke²}

Incretins have attracted the attention of the medical community for a century. ${ }^{1}$ They are secreted from the gastrointestinal tract into the splanchnic circulation in response to nutrient ingestion and enhance glucose-stimulated insulin secretion. ${ }^{2}$ Glucagon-like peptide-1 (GLP-1) and glucose-dependent insulinotropic polypeptide (GIP) are the two incretins identified in animals and man. They are thought to be responsible for about $50-70 \%$ of glucose-stimulated insulin secretion after a meal. ${ }^{2}$ GLP-1 has attracted particular attention since its identification 20 years ago because of its potent insulinotropic activity, inhibition of glucagon secretion, retardation of gastric emptying and also an anorectic effect. GLP-1 is a post-translational proteolytic product of the proglucagon gene and is formed by enteroendocrine L cells mainly residing in the distal ileum and colon. The effects of GLP- 1 on $\alpha, \beta$ and $\delta$

\footnotetext{
${ }^{1}$ Department of Gastroenterology \& Hepatology, Academic Medical Center, University of Amsterdam, The Netherlands; ${ }^{2}$ Department of Medicine II, Klinikum Grosshadern, University of Munich, Germany

Correspondence to: Professor Ulrich Beuers, Department of Gastroenterology \& Hepatology, G4-213, Academic Medical Center, University of Amsterdam, PO Box 22700, 1100 DE Amsterdam, The Netherlands; u.h.beuers@amc.uva.nl
}

cells of pancreas islets and on other target organs including the lung, heart, kidney, intestine and various regions of the central nervous system are mediated via a specific 7-transmembrane-spanning, G-proteincoupled GLP-1 receptor (GLP-1R). ${ }^{2}$ In pancreatic $\beta$ cells, GLP-1 stimulates insulin biosynthesis and secretion via receptormediated activation of classic cAMP- and $\left(\mathrm{Ca}^{2+}\right)_{\mathrm{i}}$-dependent signalling pathways. It also enhances $\beta$ cell proliferation via protein kinase A (PKA)- and mitogenactivated protein kinase (MAPK)-dependent signalling, and inhibits $\beta$ cell apoptosis via phosphatidylinositol 3-kinase (PI3K)- and protein kinase B (PKB)/Aktdependent pathways. ${ }^{2}$

The active peptide, a GLP-1(7-36) amide, is rapidly degraded to its inactive metabolite, GLP-1(9-36) by dipeptidylpeptidase-4 (DPP-4, CD26), a ubiquitously expressed enzyme. The plasma half-life of GLP-1 is very short ( $<2 \mathrm{~min}$ ), making it unattractive for therapeutic application. Therefore, promising therapeutic strategies in type 2 diabetes mellitus focus today on administration of bioactive DPP-4-resistant GLP-1 analogues or homologues and DPP-4 inhibitors. The former are of particular interest as a potent DPP-4-resistant GLP-1R agonist isolated from lizard, exendin-4, is available for administration as an antidiabetic drug in humans. ${ }^{3}$

The recent identification of both GLP-1R expression and GLP-1 secretion by proliferating cholangiocytes has set the stage for unravelling novel and intriguing functions of GLP-1 in the hepatobiliary tract. ${ }^{4}$ Cholangiocytes are the target of immunemediated attack in various chronic cholestatic hepatobiliary disorders in adults and children which slowly progress to cirrhosis and liver failure. Among these, primary biliary cirrhosis (PBC) and primary sclerosing cholangitis (PSC) are the most frequent adult diseases, leading to death after about 10-15 years without adequate treatment. Chronic cholangiopathies are characterised by increasing transdifferentiation of proliferating cholangiocytes towards a neuroendocrine cell type. ${ }^{5}$ Finally, an imbalance occurs between enhanced cholangiocyte death via apoptosis that prevails over adaptive cholangiocyte proliferation resulting in ductopenia. ${ }^{6}$ The proliferative response of cholangiocytes as a key repair mechanism of the liver in various types of liver injury-arising from proliferation of pre-existing bile ductular cells, but also from differentiated progenitor cells ${ }^{5}$-and their central role in fibrogenesis are apparently linked to their transdifferentiation into neuroendocrine cells and, thereby, their ability to secrete different growth factors, neuropeptides, hormones and cytokines, in order to communicate in a paracrine fashion with neighbouring cholangiocytes and other liver cells. The proliferative response is, thereby, mediated by neuropeptides, such as neural growth factor (NGF), dopamine, acetylcholine, epinephrine and calcitonin gene-related peptide (CGRP), or neuroendocrine hormones, such as growth hormone (GH)/ 
insulin-like growth factor (IGF) 1, oestrogens, prolactin and GLP-1. ${ }^{45}$

In the present issue of Gut, Marzioni et al (see page 990) further characterised the potential role of GLP-1 in the polyphonic cholangiocyte response to cholestatic injury. ${ }^{7}$ They show in an elegant series of experiments that the stable GLP-1 agonist, exendin $-4,{ }^{3}$ prevents glycochenodeoxycholic acid (GCDCA)-induced Bax mitochondrial translocation, cytochrome c release and caspase 3 activation (in other words: bile acid-induced apoptosis) in rat cholangiocytes in vitro via a PI3K-dependent mechanism. ${ }^{7}$ Furthermore, exendin-4 prevents cholangiocyte apoptosis and bile duct loss in bile duct-ligated rats exposed in vivo to $\mathrm{CCl}_{4}$, an experimental model of ductopenic cholangiopathies. ${ }^{7}$ The authors, thereby, substantiate their former speculation that GLP-1 analogues might be effective in slowing down ductopenic cholangiopathies. ${ }^{4}$ Still, this is the first rodent in vivo model of shortterm injury in which an antiapoptotic and protective effect of GLP-1 has been demonstrated. This in vivo model also does not exactly reflect the liver involvement in ductopenic disorders in humans. Therefore, confirmation of these promising effects of GLP-1 in additional experimental models including one mimicking advanced chronic cholestasis is warranted. Adverse effects of GLP-1 analogues such as nausea and vomiting may hinder some patients with cholestatic disorders from obtaining long-term treatment, whereas hypoglycaemia due to GLP-1 monotherapy is mostly not observed. A number of other concerns need to be addressed before GLP-1 analogues can be considered for clinical evaluation in patients with cholestatic ductopenic disorders such as PBC or PSC.

Ursodeoxycholic acid (UDCA) is the standard treatment for PBC. Up to twothirds of patients show an adequate response towards UDCA with a good long-term prognosis not requiring additional medical treatment. ${ }^{8}$ Taurine-conjugated UDCA (TUDCA) has potent anticholestatic and antiapoptotic properties. ${ }^{9}$ Like exendin-4 in cholangiocytes, TUDCA has been shown to antagonise GCDCA-induced apoptosis in hepatocytes by inhibiting Bax mitochondrial translocation, ${ }^{10}$ mitochondrial cytochrome $\mathrm{c}$ release and caspase 3 activation in a PI3K-dependent fashion. ${ }^{11}$ The protective action of TUDCA on cholangiocytes $^{12}$ like that on hepatocytes ${ }^{9}$ in experimental cholestasis is mediated in part by $\mathrm{Ca}^{2+} / \mathrm{cPKC} \alpha$-dependent mechanisms, and GLP-1, like TUDCA in cholestatic hepatocytes, stimulates pancreatic $\beta$ cell secretion via $\mathrm{Ca}^{2+}$-dependent mechanisms. ${ }^{2}$ Considering these potential similarities in the mechanisms of action of GLP-1 and TUDCA at the cellular level, one might doubt that just the one-third of patients with $\mathrm{PBC}$ who do not respond adequately to UDCA treatment and are in need of alternative/additive treatment options $^{8}$ might adequately respond to GLP-1 analogues. For these patients, treatment strategies with mechanisms of action clearly different from UDCA conjugates might be advantageous. Therefore, it appears crucial to demonstrate an additive antiapoptotic and cytoprotective effect on cholangiocytes of GLP-1 analogues beyond that of UDCA amides in experimental cholestasis before clinical studies are designed.

Patients with other inflammatory biliary diseases such as PSC and, to some degree in adults, cystic fibrosis-associated liver disease carry a risk of developing cholangiocarcinoma during the long-term course of their disease. GLP-1 analogues exert not only antiapoptotic, but also proliferative effects on pancreatic $\beta$ cells. ${ }^{2}$ An antiapoptotic and proliferative treatment strategy might be potentially harmful in a disease with a lifetime risk of $10-15 \%$ of developing cholangiocarcinoma like PSC. Thus, GLP-1 does not appear attractive as a long-term treatment in these disorders.

In summary, the authors are to be congratulated for this innovative study and their extensive previous work in this field ${ }^{4}$ which has unravelled a fascinating cross-talk between the liver, bile ducts and the gut. ${ }^{14}$ Still, it may become difficult to identify the patient population which might possibly benefit from treatment with GLP-1 analogues. The authors know best that there remains a long way to go.

Competing interests: None.

Gut 2009;58:902-903. doi:10.1136/gut.2008.165688

\section{REFERENCES}

1. Bayliss WM, Starling EH. The mechanism of pancreatic secretion. J Physiol 1902;28:325-53.

2. Baggio LL, Drucker DJ. Biology of incretins: GLP-1 and GIP. Gastroenterology 2007:132:2131-57.

3. Goke R, Fehmann HC, Linn $T$, et al. Exendin-4 is a high potency agonist and truncated exendin-(9-39)amide an antagonist at the glucagon-like peptide 1 (7-36)-amide receptor of insulin-secreting beta-cells. J Biol Chem 1993;268:19650-5.

4. Marzioni M, Alpini G, Saccomanno S, et al. Glucagon-like peptide- 1 and its receptor agonist exendin-4 modulate cholangiocyte adaptive response to cholestasis. Gastroenterology 2007;133:244-55.

5. Alvaro D, Mancino MG, Glaser S, et al. Proliferating cholangiocytes: a neuroendocrine compartment in the diseased liver. Gastroenterology 2007:132:415-31.

6. Lazaridis KN, Strazzabosco M, Larusso NF. The cholangiopathies: disorders of biliary epithelia. Gastroenterology 2004;127:1565-77.

7. Marzioni M, Alpini G, Saccomanno S, et al. Exendin4, a glucagon-like peptide 1 receptor agonist, protects cholangiocytes from apoptosis. Gut 2009;58:990-97.

8. Pares A, Caballeria L, Rodes J. Excellent long-term survival in patients with primary biliary cirrhosis and biochemical response to ursodeoxycholic acid. Gastroenterology 2006;130:715-20.

9. Beuers U. Drug insight: mechanisms and sites of action of ursodeoxycholic acid in cholestasis. Nat Clin Pract 2006;3:318-28.

10. Rodrigues CM, Sola S, Sharpe JC, et al. Tauroursodeoxycholic acid prevents Bax-induced membrane perturbation and cytochrome $C$ release in isolated mitochondria. Biochemistry 2003:42:3070-80.

11. Schoemaker MH, Conde de la Rosa L, Buist-Homan $\mathrm{M}$, et al. Tauroursodeoxycholic acid protects rat hepatocytes from bile acid-induced apoptosis via activation of survival pathways. Hepatology 2004;39:1563-73.

12. Marzioni M, Francis $\mathrm{H}$, Benedetti $\mathrm{A}$, et al. $\mathrm{Ca}^{2+}$ dependent cytoprotective effects of ursodeoxycholic and tauroursodeoxycholic acid on the biliary epithelium in a rat model of cholestasis and loss of bile ducts. Am J Pathol 2006;168:398-409.

13. Wimmer R, Hohenester S, Pusl T, et al. Tauroursodeoxycholic acid exerts anticholestatic effects by a cooperative cPKC alpha-/PKA-dependent mechanism in rat liver. Gut 2008;57:1448-54

14. Beuers U. Crosstalk of liver, bile ducts and the gut. Clin Rev Allergy Immunol 2009;36:1-3. 


\section{GUT}

\section{GLP-1 analogues: a new therapeutic approach to prevent ductopenia in cholangiopathies?}

Ulrich Beuers and Burkhard Göke

Gut 2009 58: 902-903

doi: 10.1136/gut.2008.165688

Updated information and services can be found at:

http://gut.bmj.com/content/58/7/902.full.html

These include:

References This article cites 13 articles, 3 of which can be accessed free at: http://gut.bmj.com/content/58/7/902.full.html\#ref-list-1

Email alerting Receive free email alerts when new articles cite this article. Sign up in service the box at the top right corner of the online article.

Notes

To request permissions go to:

http://group.bmj.com/group/rights-licensing/permissions

To order reprints go to:

http://journals.bmj.com/cgi/reprintform

To subscribe to BMJ go to:

http://group.bmj.com/subscribe/ 